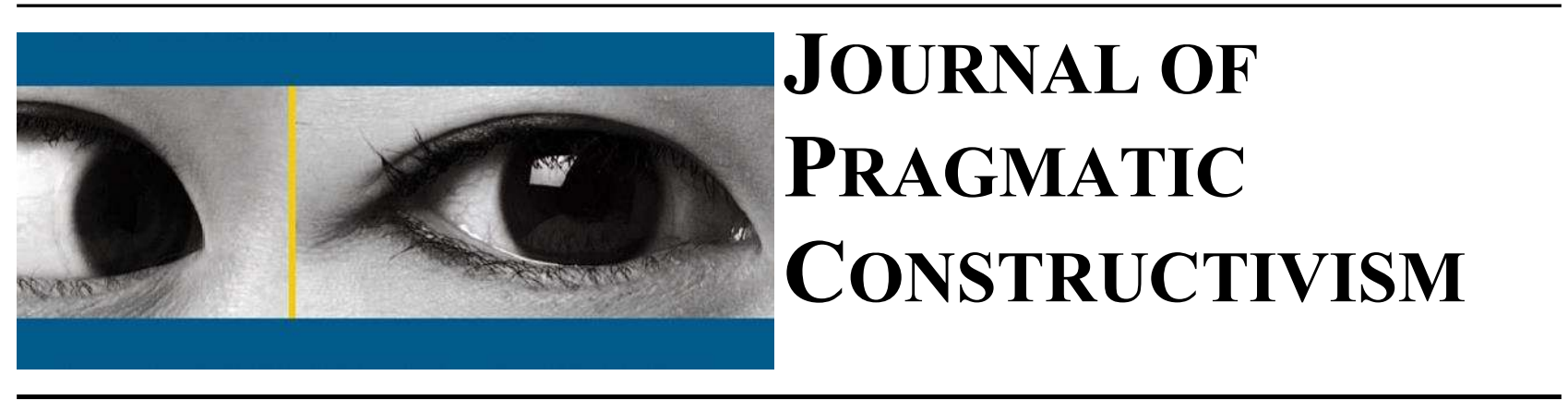

\title{
The Language Game of Goodness
}

\author{
Lennart Nørreklit \\ Professor Emeritus, Aalborg University
}

Email: lennartnorreklit@gmail.com

\section{Acknowledgements}

Thanks to Mihaela Trenca, Daniela Pianezzi, Fabio Magnacca and Morten Jakobsen for inspiring discussions. Thanks to Hanne Nørreklit for many good suggestions, and special thanks to Ruddi Welzel for truly fruitful challenges.

\section{Introduction}

\subsection{The concern}

This investigation focuses on the meaning of goodness - what it means to do good things and to be a good person.

"Good" may mean many things — it may even mean "bad." What does it mean? The introduction introduces the questions of the inquiry. Why should people be concerned with goodness? Their endeavors are concerned with survival and trying to succeed. Goodness belongs to another world. Maybe it is old-fashioned and naive?

No. People still try to do things well. They like being good at what they do. From earliest childhood, people learn to become good - to look good and behave well. They learn to become good at doing many things, for instance, to read, write and do math. They then learn to be good at doing special, complex tasks, such as those involved in their profession. Not being good at these things does cause problems.

Being good at doing things is important, but this does not make one a good person. To learn to be good at doing things is to learn to be a good instrument, a tool. If one is very good, one might compete with a robot. Robots already outperform human beings in many functions, and this trend will continue.

The above aspect of learning a skill is concerning only if the person herself is not the one using the skill. Does education primarily focus on making people good instruments? Good instruments can also be abused to do something bad. People may be trained and treated as instruments to do something good or bad, or for purposes they themselves would not agree to. Is this not what it is to be a good employee, to be good at doing things irrespective of whether it is good or bad, or whether it is something she would herself would agree to doing?

The concern for goodness permeates everything people do when they relate to others or even only to themselves. "Do I look good?," "is the food good?," "do they like me?," "did I do well?," and so on. Scenarios where the question of goodness is not important are uninteresting.

The concept of goodness is related to values. One may explain why something is good by referring to its value. How does this function, - what is the relation between goodness and values, and how do people transition from a world of facts to a world of values?

Many things that people do are good and bad. This is unavoidable. For instance, doing a job is ostensibly good, but a large number of jobs have damaging effects on the climate, which is bad. One can motivate people by the perspective of the positive aspects of their jobs while pretending that there is no bad outcome. Almost all major bad problems in modern society - wars, climate change, etc.- are caused by people's actions, although they believed that they did something good. Good and bad may be confusing concepts. Some even believe that it is good to be bad, as people fear and respect you in this case. Is the good relative to people's belief systems, as some people claim? Can these systems not be fraudulent and mistaken? Is it correct that there is no fact of the matter about the good, or is whatever 
that is believed to be good actually good? If goodness is about belief, then one would have to answer in the affirmative. But goodness is not about what people believe - beliefs do not make things good.

People are guided by their ideas of values, which are assumed to be good. Values encompass many things: to be attractive, smart, successful, impressive, beautiful and loveable, strong, feared, admired, to have power, money, and fame, to live a good life, or simply to be an honest and good person.

Although social values guide people in their judgments as to what is good, this is no proof that they are good. People's social values have been used to wage war and ruin the lives of millions. Good democracies do terrible things under the pretext of doing something good.

The justifications for people"s actions are often and with good reason treated with skepticism and dismissed as rationalizations. Whatever the reasons are for doing terrible things, the motive was presumably not to do something good, like helping the people in these countries

If people can be convinced that the worst is good, then something is wrong with people's mindset. What happened to the good people? Maybe they just want to be good instruments, good robots doing what their masters and the media say? Perhaps the responsibility for being a good person has been lost in the tiring effort to be accepted as a good instrument.

Following von Wright (Wright 1963), this study examines the function of the concept of goodness in general, i.e., not limited to one or several special fields of life as farming and healthcare. It signals a broad ethical conscientiousness. The concept of goodness is influential in almost all activities of human life. People cannot excuse rude and aggressive behavior by claiming that it takes place in another sphere, beyond the purview of goodness and ethics. People invariably influence others or themselves with what they do, and, therefore, are always in an ethically loaded situation. To reserve ethics to special subsections of our activities makes no sense. All activities have implications, and can be performed in good or bad ways and its goodness is discussed and reflected. This is reflection is considered the language game of goodness, i.e., the way the concept of goodness is used in communicative practices. It is involved in almost everything we do, even in the things we do spontaneously.

\subsection{Methodology}

This investigation to examine features of the manner in which our concepts of goodness and value function to inspire valid reflection on the issues that penetrate everything people do. People want to do good things and be good persons. To do so, they need to understand what this means. People like to be valuable and useful in the community, but in a way that they know and understand to be good. In this case, they can perform the relevant actions with confidence, love, and care. Only then will they be able to respect and like themselves and one another. Without genuine concern for doing good things, people cannot create a good world.

The method of investigation here is a conceptual analysis of goodness and value to improve our understanding of them. By focusing on conceptual relations, the insights should be basic and self-evident. The author uses a holistic approach outlining places where the concepts complement each other to generate an understanding of reality. To understand a concept is not to give a definition of it. A definition provides rules for how to use a concept but no understanding of it. On the contrary, it presupposes an understanding of the concept. To understand a concept is to understand the role it plays in the way people construct reality, i.e., how and for what purpose it is used, the kind of work it does, the activities that it motivates people to perform, and the relations in which it leads them to engage. To ensure that the interpretation of a concept has not been misconstrued it must be in accordance with exemplary usage that can be illustrated in exemplary language games (Wittgenstein 1953). The concept of a language game signifies the human form of life as one lived in cooperation based on mutual communication involving shared concepts and understanding. Methodologically speaking, exemplary language games may provide evidence for the interpretation of the concepts in use.

This investigation outlines scenarios displaying, on the one hand, the workings of good language games of goodness used in life in communities, and, on the other hand, scenarios of pure theater life, in which the games are invalid and the good is in reality bad. Social life is a mixture of these extremes, and most readers will recognize both forms. 


\subsection{Validity}

Communication is social practice based on ongoing sequences of language games ${ }^{1}$ in which speech and activities are meticulously connected through rules that connect symbols and meaning. If people understand the rules, they understand the meaning and, thus, what reality is, i.e., what actions and events are implied. Thus, the problem of validity $^{2}$ is one in relation to the reality of the communication. A lack of validity means that the communication is disconnected from reality. The implied reality does not exist, and is not even intended. The communication is just a pretense, nothing but a game with symbols.

Communication involves three levels of activities: linguistic, involving the production of sounds or written symbols; semantic, featuring the generation of meaning; and ontological, concerning reality in accordance with the meaning. The connection between speech and action in language games addresses the connection between the semantic and the ontological levels. The linguistic level enables the perception of communication. The semantic level generates an understanding of the reality concerned, and the ontological level represent the reality concerned: events and actions in the future, past, or present.

\section{Figure 1. Validity}

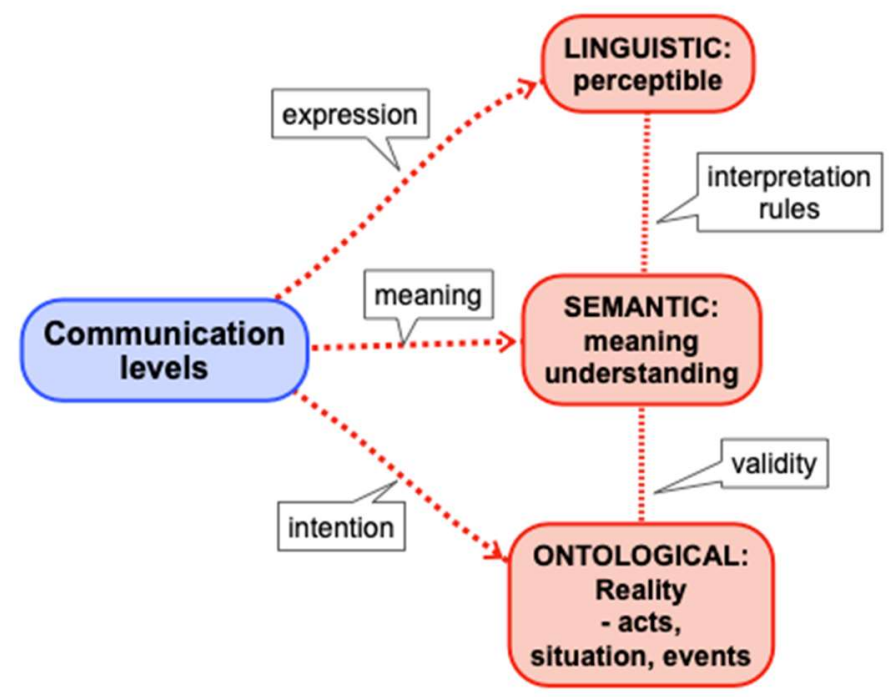

The above three levels are involved in all forms of communication, such as descriptions, decisions, and promises. They are all communicative acts that involve a perceptible linguistic level, a semantic level that outlines the intended meaning, and an ontological level that may or may not realize the meaning - the reality described, the carrying out of the decision, or the keeping of the promise. If the implied realities do not surface, the message is invalid. The exception is fiction.

People may talk about an imagined reality without knowing whether it exists. If it does not exist, their communication is invalid. People may also pretend to talk about something real to manipulate others. Such communication is also invalid: It is communicative gaming. It is sometimes a part of communicative gaming that people's expressions are ambiguous with regard to the reality of the referents of their words. It may be fictive because people mistakenly believe it to be real. Fictive plans and red flags are used to deceive others. Language games, which are deceptive and not committed to ontological implications, are what the author here calls a social theater. The problem with the theater is that some spectators and participants do not know that it is a theater.

\footnotetext{
${ }^{1}$ The concept "language game" implies that the speaking of language is part of an activity. Cf. Wittgenstein, L. 1953. $\S 23$.

${ }^{2}$ Validity is used as in methodology as accordance with reality - contrary to reliability.
} 
One problem in the world today is the focus on displaying a shining appearance of smartness. This cultivates the notion of life as a theater. In a theater, things are not for real, they are fictions; but if fictions appear to be real, they are deceptions. The grand theaters include the theaters of the politicians and media. Smaller theaters are institutional theaters, where leaders are bullying employees because this makes it appear as if they control things. To lead, they need the relevant professional knowledge, which general managers often lack. Insight has been separated from power. When this happens, the leadership is incompetent. Its communication is not honest, and cannot be trusted. The levels of stress, anxiety, and depression in society are thus rising.

The opposite to a theater is the community. It features cooperation based on understanding. The ability to reach a common understanding enables communication that can be used to organize cooperation. Communication in a community is honest. What people say has implications, and can be trusted.

The loss of validity of communication has negative consequences for people as in this case, they do not know what reality they live in. How can validity be regained? This gives reason to the question, what the difference between a valid and serious concern in a community and invalid communication used to play fake games is? How can people identify this difference? How has the validity of communication become a serious problem in a society based on science, where the hallmark of science is, after all, validity?

When people communicate to control ongoing interactions, the validity of the communication is directly evident. Although important, validity does not in itself guarantee the success of cooperation, and may fail due to errors.

If communication reflects the future, past realities, or realities that are beyond the reach of immediate perception, there is no direct evidence for it, and its validity is not directly observable. If the communication refers to phenomena that are not real, it is invalid. The purpose of speech regarding remote events may be to influence and control people by influencing their expectations. The absence of evidence enables a person to use her status to make others believe that she is trustworthy and that her communication is valid. It may, however, be easy for a speaker to disregard validity, and pretend to have knowledge and fake her intentions. In this case, she is just playing games to dominate (Bernie, 2016). A culture in which there is little scrutiny of the validity of expressions provides good conditions for gaming.

\subsection{Assessments}

Validity is a special question when goodness and values are concerned. For instance, some believe that financial values have no validity despite financial practices, while love and friendship are considered valid values. Some believe that no expression of value or goodness can have any validity. This investigation claims that whether something is good and valuable is not a question of belief. Whether and how it is possible to determine the value and goodness of things depends amongst other on the concepts of value and goodness. If, however, there is no validity concerning goodness and values, then value claims cannot not be justified, and debating them is not intellectually serious. All practices otherwise regarded as good would then be arbitrary. This study examines the validity of claims about goodness and value, i.e., their meaning and relation to the world.

Values are based on assessments of the goodness of things. Such assessments take place whenever people wonder what to think and do. How are these assessments made, and can they be valid?

Assessments unfold in communicative activities. They concern the relation between the semantic and the ontological levels. If the semantic meaning concerns goodness and values, then the good and valuable should exist at the ontological level. Is this possible? Can there be validity in such assessments, or is communication about goodness and the assessments used to justify simply part of a game that people play?

An assessment is used to analyze evidence, arguments, and demonstrations. Is it possible to demonstrate values and goodness by such means? Following Wittgenstein, one can argue that the meanings of value and goodness are in their actual use. ${ }^{3}$ However, can the use not be mistaken? After all, people sometimes change their value preferences, thereby rejecting their previous use, because they feel they had not previously understood these values. How is this possible, if the meaning just is the use? How can the use by a person be mistaken? Such changes in value perspectives involved in such changes cast doubt on the validity of value judgments. Some use must be more exemplary of a given value than others. The overall meanings of goodness and value must involve being a good person and living a good life, it seems, and this indicates their exemplary use.

The remainder of this paper is divided in two parts: Part I addresses the concepts of goodness and values, their functions in the social factory (defined below), and the formation of communities and theaters.

Part II addresses the issue of value assessments by analyzing the forms of reason with which they are justified. The analysis distinguishes between different types of reason - practical reason, rationality and scientific analysis, communicative reason, and existential reason-to determine intrinsic values.

\footnotetext{
${ }^{3} \mathrm{Cf}$. Wittgenstein's theory that meaning is use, e.g. Wittgenstein $(1953, \S 43)$.
} 


\section{Part I: Goodness and Values}

\subsection{The concept of goodness}

\subsubsection{The good among facts and possibilities}

If everything in the world are facts (for instance Wittgenstein 1922, pkt. 1), then where are goodness and values? People experience a world with values and good things. They live in a world with possibilities and make decisions to realize the good and valuable possibilities. In the world of objective facts, there are values, goodness and badness. They experience a world with possibilities some of which good. These too are real.

The recognition that people live in a world of possibilities makes the search for goodness and reasons inevitable. Possibilities are available. The question "what shall I do?" is inevitable when there are possibilities to choose from, and the answer is always to determine what is good, what is bad and what can be done to improve things. The problem is not the deterministic question of whether people have any possibilities, but which of the existing possibilities lead to something good.

People search for things and sometimes find them. They search because they are looking for something good and sometimes they find it. Sometimes people search for things other than what is because they are looking for something better. Goodness is the goal in everything they do. It is the place to stop the search. People are concerned to be in the realm of the good and take care to remain there. They are caretakers of the good. They are happy as they succeed in doing this.

People live, feel, and act in accordance with the difference between good and bad as they see it. They live not only in a world of facts, but also in one of possibilities and impossibilities, in which they can do different things of varying value. The relevant question about the world is not, whether it is facts, but whether it is good. Knowledge and facts are important and valuable only if they are related to goodness. The good is primary. The search for goodness motivates people and renders factual knowledge important, and not the other way round. The search for goodness is active all the time, in all our actions, and the answer is always an attempt to find something good. Being in the world is a search for something good. And sometimes people do find it.

\subsubsection{Importance}

People's experience shows that their choices make a difference. Whether the consequences of their choices are good is important, which makes the choice itself important. This changes the choice from a question of "what would I like to do?" to one of "what would be good to do?" It makes the question of what to do important and a search for that which is good. The difference between considering that which one desires and that which is good is that the latter involves looking for reasons to prefer one choice over another that refer to its greater importance. Spontaneous desire may not be a good reason for people's choices.

\subsubsection{Openness}

The concept of goodness is an empirically empty concept. In principle anything can be good or not good. As a concept it is an open concept. A priori it does not apply to anything. There's no "the good," "goodness itself," or "the property of being good." There is no "property of goodness" that all good things must have. Goodness is not a part of the proper description of things. A thing may be red, light, or heavy, but there is no property of goodness in its list of properties that enables us to see that it is indeed good. One can always ask whether it is in fact good.

The above empirical openness is the basis of the so-called "open question argument" by G. E. Moore, according to which no observable property, P, can define the concept "good." This is because the question "Is P good?" is meaningful, no matter what property $P$ is, e.g., happiness, health, or benevolence (Moore 1903, §13). One might object: "But of course, happiness is good!" And this is usually true. But there might be cases where this can be questioned. Therefore, happiness is not identical to goodness, and cannot define it. As this reasoning applies to any observable property, goodness cannot be defined as an empirical property. Nothing is good or bad a priori. 


\subsubsection{Assessment}

Although goodness cannot be defined as an observable property owing to its conceptual openness, the same openness makes it possible for anything to be good in principle. Because nothing is good a priori, one can always make an assessment of whether it is good a posteriori. The logical difference between goodness and facts is not a gap, but a theoretical difference between assessment and description. It is not a gap between different types of realities. Goodness is determined by assessments, which are different from empirical description. However, an assessment is based on describable empirical realities. This applies to all forms of ethical and other normative judgments.

For something to be good, it must be important. That is a criterion for choosing one action from among the given possibilities. Importance is not a property of something like for instance weight, but a specific relation the object has to something else. Assessments analyze whether a certain object is important to something. The assessment finishes with a judgment that attributes a special status of acceptability or not acceptability to the given action or thing: Being good means that it is acceptable, and that no improvement is needed. If it is not good, improvement is needed for it to be acceptable. By being assessed as good, things are no more mere facts. They have been given significance and meaning in the world of people. If something is good, people use it, try to protect it, enjoy it, and feel happy about it. If it does not achieve this status, they do not trust it.

To sum up: The concept of goodness is characterized by openness and importance. Assessments involving reasons are used to determine what is good, thereby giving it a status as something valuable and worth caring about.

\subsection{The social factory}

\subsubsection{The primary game of goodness}

The social factory is the practice that makes people social. It is their communicative interaction, their language games, i.e., interactions as interwoven, with the exchange of communicative expressions in exemplary validity. It begins with the mutual communication of good—-smile, laughter, and excited movements, the signs that it is good-and is sometimes replaced by signs that something is bad - crying and worrisome expressions. This is the primary language game of goodness. Out of this game, everything develops: language, interaction, understanding, and communication. Every step on the way involves signals of good or bad. The language game of goodness is the developer and daily administrator of people's form of life.

In general, the language games make people social beings; special language games form the special cultures and make people the type of people they are. The real motivator that is intrinsic in each language game is the game of goodness. This is the control system of the social factory.

\subsubsection{Usage}

The term "social factory" was originally developed by Italian autonomist Marxism for the analysis of the expansion of capitalist social relations with society as a whole (Tronti, 1962; Thoburn, 2003). It is now used by online companies in a different meaning that focuses on creativity and online presence. The use of the concept in this investigation is different. Here, it means that the language game, with its intertwining of communication and action, is the medium using which the person develops as a social being. The constant adjustment of mutual expectations in the language game is wired into people's brains. This means that good social norms as well as social problems are programmed in the social factory. The usage of the term in this study focuses on primary social interaction- the language game - as the factory that forms the person. It is not a deterministic machine that stamps a personality on the person; on the contrary, the person forms herself to be able to function based on her experiences of participation in the interaction.

\subsubsection{The factory at work}

From early interplays between child and mother to professional, high-level communication in the lives of people, each practice involves different forms of communication, where each is a sequence of language games. Each small game meticulously follows specific rules, all aiming at organizing interaction through processes of understanding. In this process, the social skills and personality develop, and the person becomes the type of social being she is. What kind of being that is depends on the games she participates in and how she manages to participate in them. These patterns are wired into her brain, and determine how she acts. 
That which motivates people in this development is the constant signal of goodness. It signals importance, bestows recognition and status, and makes people feel good. People connect, feel well, and are motivated where they experience this recognition and appreciation, whether it is verbal or not.

The language of positive assessment, appreciation, and recognition is fundamental to social development. It is fundamental in pedagogy, leadership, politics, and any profession that involves any form of communication-based cooperation. Mastering this is to become a caretaker in the creation of good relations. The language game of goodness is the fundamental instrument to organize and influence. Although soft, it is the strongest motivator available. People are observant of how the other expresses positive assessment and appreciation: Are her assessments credible and reliable, are they positive, is she biased, is she making any assessment, or is she unobservant? The skill to make and express good assessments is a sophisticated and vital game of goodness that influences social practice. It makes people more social, and motivates them to develop and fine tune skills needed to cooperate. It is basic in best assessment practices.

If the game of goodness is not functioning properly, the motivation becomes expensive and the performance mediocre. The widespread use of brutish and aggressive control behaviors, stress, and negative motivation have bad consequences. They degrade performance and demoralize people. As a cultural trait, this undermines the attractiveness of the entire society.

\subsubsection{Practice and development}

Practice enforces and adjusts valid communication in operation. Interactive skills are developed through special educational practices. The coordination among practices involves lead activities. These aspects of practice need to be valid for the social factory to function well. The rules of the games are not simply rules of talking, but help coordinate activities.

With regard to participation in practice, caretakers reassert and adjust their cooperative skills. They combine professional skills to control advanced activities and communicative skills to coordinate with others. Caretakers need to exhibit socially constructive behavior in order to be trustworthy participants. They need an understanding of what goodness means - goodness as being a good person, including having good ethics, skills, and the ability to assess and appreciate others as well as good things. They should be able to monitor, assess, and ensure the quality of their own performance.

Professional skills unfold a technical rationality necessary for advanced practice. Communicative skills unfold a communicative reason (Habermas 1981). The combination of these two constitutes validity in interactive communication. To avoid people from acting as fake professionals, practice is needs to distinguish between superficial communicative skills and valid communication.

Development: Skills and character are not innate. Good education is imperative for personal development. This presupposes creativity and the ability to spontaneously express positive assessment, as in a smile and laughter, as a response to loving treatment. Caretakers can then support the development of the child in valid interactive games. As the person learns, she may eventually become suited for operative practice, and may even surpass prevalent practitioners and their leaders. Having more advanced knowledge than the leadership may "threaten" existing practice. To avoid this, developmental practices temper creativity.

Coordination: The coordination among practices requires governance so that they complement each other. This structure involves a combination of inter- and intra-practice modes of leadership. Intra-practice leadership is valid only if the leader possesses advanced professional skills. Without them, leadership becomes a mere game of words.

The ability of qualified development to surpass the level of understanding of leadership is a source of dissonance - call it creative dissonance — between the practitioner and the leadership.

Creative dissonance is an issue in any mode of development. It represents dissonance between a controlling practice and creative innovation. Practice is based on systemic repetition and reproduction, and favors efficiency, while innovation demands change, challenges repetition, and favors effectiveness. Nevertheless, both are part of any practice, and leadership that has a good understanding of research and innovation as well as communicative reason can handle this dilemma by guiding the requisite assessments, and combining the promotion of creativity and efficiency. Leadership that enforces itself without these qualifications is forced to replace assessment of the good with unqualified formal systems of assessment with little understanding of the good. 


\subsection{Community, theater, and paranoia}

\subsubsection{The concept of community}

In this investigation the term "community" is used to signify any group of people that cooperate, live together, and take care of one another based on a common understanding and shared values.

Kropotkin (1902) based his theory of communities on his objections to social Darwinism, which considers competition as the mechanism that leads the strongest development. By contrast, Kropotkin claims that cooperation and mutual support are the source of success, and claims that this has been widely documented in evolution.

Ferdinand Tönnies (2001 / 1887) used "community" (German, Gemeinschaft) to signify unity based on the complete unity of wills and direct mutual affirmation. Tönnies differentiates between close communities in narrow relations and various "followships" based on common professional interests. He also indicates a biological basis for strong community bonds.

It is, however, necessary to modify these elements of naturalism. Although community creates a competitive advantage and has a biological foundation, this author considers community as based on communication more than on biology. In this way, it is possible to explain not only the emergence of communities but also the many failures, dissolution and disruptions of communities - as for instance, how the expectedly biologically strong mother-child bond sometimes fails when a mother rejects the child.

This investigation defines the functioning language game of goodness as the basic manifestation of a community. The thrill and joy in in the communicative game of goodness are the constituents of social beings and communities. This is what helps form and maintain bonds. With this concept of the community, we can also analyze failures and disruptions referred to above. People that develop and live in an environment with few to no games of goodness - owing to absent or aggressive parents, peers, or leaders - become alienated from such games. This may negatively influence their personality.

\subsubsection{Communities}

A community here is based on the enjoyment of communication that generates a common understanding, an understanding in which people feel that they share values and inspire each other's perception of values. The strong will that precedes values and understanding may have an oppressive character that is incompatible with the concept of community used here.

The community is the center for the language games of goodness and valid assessments. It is here that acceptance and status have meaning. As caretakers, people of the community support one another and their values. Communities are informal constructs with or without a formal framework. They are the basic unit for people to cooperate.

Common understanding is achieved by using dialog and communicative reason to produce a platform of shared understanding. Not all communication leads to a common understanding. Some is intended to prevent such a common understanding in order to challenge the membership and function of the community. The difference between aiming for understanding and not appears in the details of the language game. The aim of establishing a shared understanding causes people to engage in dialog characterized by a meticulous care while listening and explaining oneself clearly in all communicative steps. It also involves a willingness to demonstrate the relevant ontological implications-actions, events, and situations - so that people know that the communication is not a mere game of words without validity. At each step, people are careful to signal their assessments, whether positive or negative - through minor sounds, small movements of the head, or selected facial expressions - to signal to the speaker whether she is understood.

Understanding is achieved when people can share their assessments and agree on what is good. A person who avoids these efforts is not a trustworthy community member.

The community reflects ideas to organize life in networks of activities. It shares values and ways of reasoning. A common understanding enables members to easily reach out to one another. The ongoing nature of communication as dialog reinforces a common assessment and understanding.

Each group develops special concepts and communicative practices. Departments and professions, and institutions and assemblies constitute groups based on specialized communication and understanding. To be productive, they need to achieve a common understanding of their special task in order to cooperate with and support one another.

To have the status of an accepted and trusted caretaker in a community is to be judged to be a good person. This is the function of assigning something the status of being good. It is to be good in a community, a world of common understanding. This holds for anything - an act, a performance, or a character. Additional improvement is not needed in this case. Being good means passing a threshold of recognition, and thereby attaining a status as a capable and trustworthy person who can play the intended role. If something is not judged to be good, something is wrong with it. In 
this case, it is unacceptable and cannot be relied upon. It needs improvement to be accepted. If people are not accepted as good even in the absence of wrongdoing, they may be victims of bias and discrimination.

The status of being a good person involves obtaining the recognition, until proven otherwise, of being a good person in the roles that a person plays - for instance, being a good family member, doing a good job, or doing good work in the community. To be accepted as a member in a community is to be accepted as a good person. A good person is expected to be one who acts out of love and care, with understanding, empathy, and skill. Communities rely on its members being good persons. Being a good person is even more important than having a good life. People need to be recognized as good people by society and by themselves. They also require that their life, and the things and relations that belong to it - their family, friends, properties, and interests - are recognized as good, and are therefore protected.

If a person is excluded from participation in valid communication, she is in a lonely and precarious situation. Her status as a good person is challenged. A society that imposes too stringent a set of standards on its members, or makes them so biased and fuzzy that many cannot achieve them, does not respect people as good citizens. Society can undermine communities, and cause people to live under the stress and fear of losing their jobs and ability to contribute to the community.

\subsubsection{Winning and losing}

There are many types of games; some are win-win games and others are win-loss games. Often a game is a competition where one participant wins and the other loses. Playing games may be a challenging undertaking in which people can hurt and even destroy each other by inflicting loss of money or status.

In a community, people play competitive games for fun, and not in order to hurt and exploit one another. The most widespread game play - the ongoing language games of goodness that organize life through common understanding - is, however, a sheer win-win game. Nobody loses, unless everybody loses. Language games in a community pertain to understanding in order to realize goodness. Many other communicative games are win-loss games. They are about positioning, dominance, and victimizing the other.

When minor children play freely, they do it for fun, and not just to compete and win. All games of goodness involve fun, interaction, cooperation, supporting each other, and development. These are the basic games in life relating to doing good things in good ways. When games begin to designate winners and losers, this may still be entertainment and fun, but may also turn into sinister games about domination and depriving the other of status and wealth.

Although competition is an exciting motive in many games, radical competitiveness, i.e., where each interaction is a competitive game such that one must try to win because they otherwise lose, is a false description of the human condition. Communication and cooperation are not about competition but about performance, truth, and understanding. The beliefs in universal egoistic competition have been promoted in some theoretical perspectives. This is not, however, the primary driver of social interaction, let alone that of communication.

Communication is by nature a game of goodness, and this makes it a win-win game in which people not only achieve a common understanding of life and one another, but also produce good and even great things. The aim of goodness nurtures creativity and improvement, and easily solves the problems of dissonance it produces. The language games pertaining to understanding, truth, knowledge, and values are all win-win games. If one in the community makes an improvement, everybody benefits.

\subsubsection{The theater}

The word theater is used in a metaphorical sense here. In the theater, the communicative game is a struggle for domination and submission. It is gaslighting and psychological wargames in a polished disguise. The topics of communication may appear to be sincerely intended, but in the theater, they are fake and invalid. The only thing that is not fake is the game of power and domination. People who are genuinely concerned with the substance of the topics are run over. Everybody on the scene must present themselves as being on top and successful, regardless of whether they win or lose. In the theater, losing is to look like a loser. In a community, on the contrary, losing is the inability to recognize one's errors.

Many communicative games are pure theater games about power and domination. These are games in the sense that they are about appearance and not the realization of any values. But these are sinister games because they aim to hurt the other.

The semantic level does not reflect something real in the above context. In the theater, only the theater is real. Everybody plays her personal I-game (ego-game) according to personal rules. A person is either a strong player or they must ally with one. Winning is about creating the best alliances and making the opponent look beaten, weak, and making them leave the theater. It pertains to traps and illusions. Large parts of public life organized by the media have turned into a theater. The games have audiences that cheer for their favorites. Similarly, management has often turned 
into a theater where leaders are playing I-decide games without understanding what they are "leading," and, therefore, are unable to do something valid and real. A large number of decisions and plans are hence made that mean nothing. Besides domination and submission, I-games have no content.

The games in a community, on the contrary, are games of common understanding, values, ideas, and reasons. No such thing exists in the theater. The theater is not concerned with cooperation. Cooperation presupposes common understanding, which neither exists nor is intended in the theater. It is a world of competition and combat. To be good is to be able to win not by being nice and good, but by being mean while pretending to be good. I-games use toxic communication. The dominant players are master players who achieve powerful positions although they lack the relevant competence. Only toxic leadership treats the organization as a theater, where it creates illusions about its goodness, and fear and paranoia about the bad to consolidate its power. This is tantamount to psychological warfare. It has no content, is a waste of time, and a painful experience for many.

There are no caretakers in the theater. If people mistakenly believe that the games are valid and real, they are in trouble.

\subsubsection{The two scenarios}

The distinction between community and theater can be illuminated by Burke's model for social interaction in his grammar of motives (Burke, 1945). Burke's model distinguishes among five principal elements: the act comprising deeds and thoughts, the scene comprising the situation and background of the act, the agents comprising the persons performing the acts, the agency comprising the means and instruments used, and the purpose.

Acts: The theater treats an act as that which happens at the scene in communicative exchange - the exchange driven by the I-games is the real event. The games are ad hominem games, and their consequences are the outcome of the win-loss struggle. This makes them very painful for gullible people not aware that they are in a theater.

Communication is not committed to validity in this case.

Actions carried out from the perspective of the community concern the realization of values, and the specifics of communicative acts concern the establishment of a common understanding for ways to mold actions beyond the communicative scene. Communication molds the acts of caretaking beyond the communication itself.

The scene: The theater treats the here-and-now scene as the reality, and disregards anything beyond as irrelevant to the act. The actors may well regard a world beyond the here-and-now scene as relevant, but the reality that concerns them is not the direct topic of the communication.

The community considers the here and now as part of a larger scenario, the reality of the community. The meaning of its communication is the commitments to and implications of the larger scenario.

In practice, community practice and theater gaming are intermixed, and this creates severe problems. A significant part of pure theater gaming involves pretending that the communication is valid; and if the players have power, they may switch as they please between drawing consequences or not.

The agents: The actors in the theater are players. Actors in the community are caretakers of its values. The concept of the agent is interesting. According to one meaning, as used by Burke, it is used to identify the source of deeds, and denotes the person who acts. Call this an I-agent. A different but common use of the concept in practice, as well as in the agency theory, is that of a person who acts on behalf of another. Call this the r-agent (representing "acting on behalf of'). Actors in the community are r-agents because they take care of values that serve its members. In the theater they are I-agents.

The agency: In the theater the tools are all kinds of tricky language games that are able to confuse the other and make the other unaware what the real stance and intentions of the actor is.

In the community, meticulous epistemological scrutiny is used to ensure valid common understanding here and now, which leads to viable coordinated action in the larger scene.

The purpose: In the theater, the purpose is to teach the other a lesson and win the here-and-now battle to achieve dominance, while avoid defeat at all cost. From a community perspective, such a purpose is futile.

The game of goodness in the theater is all about winning and domination. The game in the community, however, is an uncomplicated game of goodness.

\subsubsection{Paranoia}

Plato made "the good" a central concept in ethics, as the overall ideal motivating all activities. Alternatively, the desire for happiness has been considered the motivation behind human activity by many.

If a person does not aim to be good, how can she respect herself? The story about herself — which actually is a part of her-will either tell her that she is good or tries to be a good person, or that she is not or does not try to be one, depending on whether her memory deceives her. Here is a source of self-respect. Giving up on doing good and 
accepting doing bad is giving up on self-respect. It is not sufficient for one to gain the respect of others; one needs to obtain it from oneself as well. To earn the respect of others, one needs for them to recognize that one is good. To earn one's own respect, one needs to be convinced that one did things as well as one possibly could. Doing good is a commitment for one's life, to make it as valuable as possible.

If a person claims to be motivated by a desire to do good, a psychological rationalization theorist may claim that this is a defense mechanism, and that the subject is actually motivated egoistically by her desire for happiness.

A Platonic rebuttal could be that this may look so from a superficial point of view. In reality, the problem is that she does not know what goodness is. Her culture, the social factory, has educated her to believe that people are motivated by happiness, therefore she believes that happiness is good. Her motive is in reality to do good and be a good person, but her understanding of goodness is misleading. She aims at the good but has no valid understanding what that is.

Here is the problem that needs to be solved: Either bad things are done because people are evil and bad, and therefore intend to do bad things when it serves their evil purposes; or people do bad things because they are confused and mistaken about what the good is - conflicting and painful personal experiences may cause such mistakes.

A third possibility that is believed by many, is that one or the other of the above explanations apply depending on the instance. For instance, the one explanation applies to some people - the good ones - and the other explanation applies to other people - the bad ones. This is a paranoid mindset. It is paranoiac in the sense that it arbitrarily defines who is good and bad, and then interprets the available empirical information accordingly. This procedure is epistemologically fraudulent, and forces the conclusion to define the evidence.

This schema penetrates many cultures, including Western culture. All the heroes are on the side of the good, and are fighting against the villains on the evil side. This mindset is pervasive as if people all are paranoiac: we the good race, nation, civilized, pious, good hearted, diligent, female, gentle, leaders etc. - the other the bad - race, nation, barbarians, atheists, evil hearted, lazy, male, molesters, employees etc. The good-bad/evil schema is constantly in use.

The above mindset is clearly irrational and flawed. Nevertheless, it penetrates media, politics, and leadership as well as discourses at all levels. Its invalidity makes it suitable for use in malicious games and grand theater.

What is the difference between a paranoid and a valid assessment? The paranoiac predefines the I-side as good and the others as bad. This leaves no room for a valid assessment. In fact, it leaves no room for any assessment at all because the conclusion is given a priori, and is used to select and interpret the evidence. The concept of goodness is predefined by some such empirical features as nationality, race, social position, and gender. This violates its openness.

The paranoiac mindset forgets that the other, which it assumes is on the bad side, does the same: They live in communities ruled by their language games of goodness, where they are caretakers trying to realize and protect their values. Overlooking this is inconsiderate. Maybe the others are not possessed by hatred and aggression toward others, or maybe they have the same paranoiac mindset against the other? The paranoiac mindset is the evil. It is founded on irrational fear and inadequate knowledge.

The origin of such mindset may be traced to inadequate workings of a social factory, which may make people susceptible to a fear that overrides their ability to use good reason, and instead causes them to serve as instruments in the belief that they serve the good.

\subsection{Ethics of the good and the best}

\subsubsection{The ethics of the good}

The community has been defined as a group with a common understanding based on an ethics that recognizes the good, i.e., of people and things that assessed satisfy the standards that the community expects. People are accordingly motivated by the desire to be good people. Good cooperation is a win-win game. This enables communities to function internally as well as in cooperating with other communities to form larger societies. The common desires to create a good world can enable all societies to unite and organize for global cooperation.

The ethics of the good uses a measure of assessment that a significant group of people, in principle everybody, can satisfy. It is important to enable people to pass the norms and standard and avoid becoming losers.

Norms and standards may produce static patterns, which makes the community become backward.

\subsubsection{Ethics of the best}

An alternative to the ethics of the good is to organize practice according to an ethics of the best, i.e., an ethics in which only the best achieves recognition. Personal endeavors in such ethics are similarly aimed at becoming the best. It seems logical to improve practice by implementing an ethics of the best to counter weaknesses of the ethics of good. It 
is a world of competition. And it promises excitement and progress. The "win-win" of the ethics of the good is replaced by a "win-loss" of the best.

A capitalist economy is based on competition. Only the best can win and achieve recognition. It is not good enough to be simply good. A society of competition is not concerned about the good but the best. To be good means nothing and being the best means everything.

There are some downsides to an ethics of the best. The obvious downside is that only one can be the best. All others fail. They are losers, which leads to low self-esteem and inculcates a negative character in society that produces inequality. People will be motivated by fear of becoming losers. The ethics of the best is that it dissolves standards and norms. There are norms for being good but there cannot be a norm for the best. Cooperation becomes competition, partners become competitors. The community transforms in the direction of a theater, that eventually may challenge the existence of the society.

\subsubsection{The good and the best}

To illuminate the consequences of the two ethical perspectives, the difference between good and best needs to be clarified. The best and the good are different concepts. They signify different things. It is false that the best is always better than the good because the best may not be good at all. If all are bad, then still one can select the best, but this will be bad and not good. The best is a comparison that signals the top of a group on a scale. It does not guarantee that anyone on the scale is good because it does not include references to standards of goodness. The good, on the contrary, is not judged by a comparison between competitors but by reference to standards that guarantee an acceptable level of quality. To a community, goodness is significant. The ethics of the good leads to the development of communities. The personal motivation to do things as well as possible enables the ethics of goodness to deliver performances where all participants give their best.

The ethics of the good and the best are of course ideal types. In practice the good and the best work in combination. To maintain the community, it uses standards of goodness that people in general can fulfil so that they can achieve recognition. Thus, groups of recognized participants are created that can cooperate and also compete. The personal motivation is to be good according to social standards as well as to personal ability. The personal drive to deliver the personal best leads to new knowledge and skills that spread to society and gradually improves the standards for the good.

\section{$2.5 \quad$ Values}

\subsubsection{Objectification}

In assessments, the goodness of things may be judged by reference to the values to which they contribute. To call something good is to judge it as having importance and assign it a status as a value. A value is conceptualized goodness, where this conceptualization is applied to assessments.

Although values in practice are used to legitimize assessments, the objectification of the value is itself based on thorough assessments of the goodness of things. These assessments are values conceptually attached to empirically recognizable features based on their presumed goodness. Goodness is the lead concept in the assessment and values are the outcome. The attachment is a social objectification of goodness, a construct. In practice, it operates as follows: By knowing these values, people can determine the specific goodness of things.

While goodness is an open concept, values are the conceptually objectified results of assessments of the social factory, institutionalized and integrated into the social structure. Health is one such concept. Health is considered good and therefore given the status of a value. It is a descriptive concept that is loaded with the status of value. The value load even influences the way in which its descriptive content develops over time. Because health is a value concept, everything that contributes to health is automatically considered to be good and valuable. Other values include life, shelter, gentleness, skill, beauty, generosity, cleverness, love, interestingness, and inspiration. They are all conceptualized forms of goodness.

All concepts, even the most descriptive ones, contain a certain element of value, namely the value that legitimizes the existence of the concept, the reason for why we have it. Not only are values conceptually attached to empirically recognizable features, the reverse is also the case. Empirical features are conceptualized because they represent some value. The integration of value and empirical features is the result of assessment-related activities that are always a part of people's approach to things. The closure of an assessment is the objectification of the integration. Objectified values constitute practice as guidance for the kind of things that are to be done, making it superfluous to 
start analyzing from scratch every time people are to do anything. The conceptual system is loaded with value-based guidelines.

\subsubsection{System}

The values of a society are part of a complex web. Everything fits into the web in several ways. Some basic values signal the basic system of values of society and everything else is assessed according to how it realizes these values. The system of values is implemented in institutions in the form of health, justice, law, democracy, education, economy, science, art, culture, and even nature.

The realization of values is based on regulation by social control systems, and professional, value-oriented, and specialized skills related to the economy, political system, legal system, and research and education. The realization is run by professional communities that offer their values as service to society. If communities turn into theaters, the service to society becomes fake. If, for instance, the military is controlled by a theater, the use of military power in a foreign country is likely based on paranoiac arguments, and benefits for the community or anyone else are non-existent.

\subsubsection{Re-evaluation and change}

As society changes, its values are adjusted. When objectivized values conflict with needs and opportunities, the values are re-evaluated and the institutions transformed.

The rational basis for the re-evaluation of values is the interplay between the openness of the concept of goodness and the objectification of value concepts. By questioning the goodness of the values, people re-start the assessment process. Most re-evaluations change some values while leaving basic values such as health intact. Such a reevaluation builds upon pre-existing value foundations.

This leads to the question: How are the most fundamental values established? To clarify that the investigation needs to analyze what value and goodness mean to people. Neither society nor the community is a goal in itself. They provide a framework that serves the life of people.

\subsubsection{Needs}

An objective approach to values is to identify them with needs. Social values and institutions aim to satisfy a system of needs such as physical and social as well as the need for self-actualization (e.g., Maslow, 1943). Accordingly, everything that satisfies a need is a value, and vice versa. All values are instrumental values serving satisfaction of needs. The value system is an interconnected system of means to satisfy needs. All the needs condition one another and must all be fulfilled. If one need suffers, the entire system suffers. The goodness of an instrumental value is explainable by its beneficial consequences for another instrumental value.

The problem with such models is that they address only needs and instrumental values. Such a value chain requires intrinsic, non-instrumental values. For instance, needs are a condition for life. If life is a value, then the fulfilment of needs is valuable. But if life is worthless, then the fulfilment of needs is worthless as well.

The value of life cannot be reduced to its conditions. Paradoxically, for life to be meaningful and valuable people need to do things, which they do not need to do in order to live. For instance, they need to do things that turn their lives into a story that they like and feel good about so that their existence is not a waste of time. An instrumental approach to values cannot stand alone.

\subsubsection{Good-bad}

Although values are an objectification of the good, bad values are objectivized and exist as well. Use of weapons, spying, jailing, killing, pollution, cheating, stealing, and war are not counted as values. They are performed under the pretext that they are good and some of them represent significant economic value. While some of these 'bad values' are crimes that conflict with society, the worst of them such as waging war are in accordance with society. Economically, the bad phenomena also have a price and thus an economic value. Thus, things have a value no matter whether they are good or bad although people would like an economy where only good things have value. The fact that it is possible to argue in favor of bad values signifies the need for a re-assessment. 


\subsubsection{Valid-fake}

The main problem in assessment is that of validity. Any re-assessment can be argued for if there is no demand for validity. Assessments must be valid. Consequences of invalid assessments are severe. If assessments are not valid, the resulting value objectifications are invalid, and the value construct is mistaken: an illusion with bad consequences instead of good. Fake values lack ontological integration. They are simply words that may claim: "We bomb the country for the good of the people." The invalidity of that claim is demonstrable through recent examples. The real reason for bombing a country may be, for instance, to control its natural resources, assuage the military-industry complex, or something else.

Invalid assessments can succeed in decision making because they operate in a theater. The theater is devoted to creating fiction although this may jeopardize people's lives. Its storytelling is not validly connected to real occurrences. Valid values are realized by communities in which words have meaning for the caretakers who use them in consonance with their actions. When the values referred to in an operation are fake, as in the "value of the bad," they turn life into a theater, which then features I-games that do not create anything but show, although it may be deadly. Communities make values real whereas theaters do not.

\subsubsection{The personal}

To organize life, people need to develop personal values. They need them in order to contribute to the community and give a meaningful structure to their lives to gain self-respect. ${ }^{4}$ People with personal values become caretakers.

Without personal values a person may act impulsively and incoherently, or she may become follower of a dominant person, opportunistically going along with her values. She is just an instrument. She is not a caretaker of values but a player in a theater. In a theater, values easily change. There is nothing wrong with following another person who is taking the lead if they exhibit personal values that contribute to the life of a group or society. It is, however, a problem if one does so because one has no values of one's own.

If a person's only values are to play games to control other people, she is a player and no caretaker of values. She may be a great actor on the scene. However, to be a leader she needs to personally have and understand good values, in addition to the ability to lead and inspire people to contribute. Without personal values, this is not possible.

A powerful player can make many people her instruments. But without personal values, she and her instruments have nothing to contribute. The lack of personal values makes her hollow. In the end she is herself just an instrument used by other players. Without personal values, she can do nothing but play a role in a theater.

The social factory fails when it prevents the child from developing personal values. Personal values develop from personal experiences, where the subject uses her desires, experiences, and decisions to try things she likes and things she can do, learn who she is, and how she reaches understanding and cooperation by contributing.

In the formation of her values, the person relates to the values of society and projects herself as playing a certain role. She imagines and strives for a merger between her values and those of society. In the process of cultivating her personal values she aims at becoming a person taking care of these values. For instance, her concern for the value of justice may lead her to become a lawyer and become involved in legal institutions. The personal role defines who she is: a judge or an attorney. She is not an actor playing a judge in a theater, but a caretaker of the values of justice.

When a person identifies herself as "I am married to ...," "I am a secretary in ...," or "I am a lawyer," it is important for these identifications to express her personal values. Otherwise, she is not a caretaker but a player who, at some point in her life, may discover and recognize that she has deceived herself.

\section{Conclusion and further research}

Goodness is the leading concept in the formation of values based on valid assessments. It is open, and can thus support the re-evaluation of values. The social factory penetrates the functions of the language game of goodness. It succeeds in constructing communities of caretakers based on a common understanding and values, but sometimes it fails and enables development of theaters in which the bad is the good. However, people are not instruments. They have a life in which they have to realize responsibility and dignity. To this, they need personal values.

\footnotetext{
${ }^{4}$ See self-determination theory for research on the importance of personal values and motivation (cf. Ryan \& Deci, 2000.)
} 
These values need to be valid and intrinsic. To investigate how values can be valid and intrinsic, The Language Game of Goodness, Part II: On Reason analyzes the forms of reasoning involved: scientific rationality, practical reason, communicative reason, and existential reason.

\section{Literature}

Bernie, Eric. 2016. Games People Play. The Psychology of Human Relationships. London. Penguin.

Burke, Kenneth. 1945. A Grammar of Motives. New York: Prentice-Hall, Inc.

Habermas, Jürgen. 1981. Theorie des Kommunikativen Handelns. Suhrkamp. Frankfurt am Main.

Kropotkin, Pjotr Alexejewitsch. 1902. Mutual aid: A Factor of Evolution. Work incomplete.

https://en.wikisource.org/wiki/Mutual_Aid:_A_Factor_of_Evolution

Maslow, Abraham. 1943. A Theory of Human Motivation. Psychological Review. Vol. 50 No. 4, pp. 370-396. https://doi.org/10.1037/h0054346

Moore, George Edward. 1903. Principia Ethica, Cambridge University Press. §13.

Ryan, R.M. and Deci, E.L. 2000. Self-Determination Theory and the Facilitation of Intrinsic Motivation, Social Development, and Well-Being. American Psychologist. Vol. 55. No. 1, pp. 68-78.

Thoburn, Nicholas. 2003. Deleuze, Marx and Politics. London: Routledge.

Tönnies, F. 2001. Community and society (1887). Ed. Jose Harris. Trans. Jose Harris and Margaret Hollis. Cambridge, Cambridge UP.

Tronti, Mario. 1962. Operaismo in English. Retrieved 6 May 2017.

Wittgenstein, Ludwig. 1922. Tractatus Logico-Philosophicus. Kegan Paul, Trench, Trubner \& Co. London.

Wittgenstein, Ludwig. 1953. Philosophical Investigation. Basil Blackwell. Oxford.

Wright, Georg Henrik von. 1963. Varieties of Goodness. Routledge and Kegan Paul 1963.

https://www.giffordlectures.org/lectures/varieties-goodness. 